\title{
Polymethylmethacrylate-assisted ventral discectomy: Rate of pseudarthrosis and clinical outcome with a minimum follow-up of 5 years
}

\author{
Mario Cabraja*, Daniel Koeppen, Wolfgang R Lanksch, Klaus Maier-Hauff and Stefan Kroppenstedt
}

\begin{abstract}
Background: Polymethylmethacrylate (PMMA) assisted ventral discectomy has been criticized for high rates of graft migration and pseudarthrosis when compared with various other fusion procedures for the treatment of cervical degenerative disc disease (DDD), therefore rendering it not the preferred choice of treatment today. Recently however spine surgery has been developing towards preservation rather than restriction of motion, indicating that fusion might not be necessary for clinical success. This study presents a long term comparison of clinical and radiological data from patients with pseudarthrosis and solid arthrodesis after PMMA assisted ventral discectomy was performed.

Methods: From 1986 to 2004416 patients underwent ventral discectomy and PMMA interposition for DDD. The clinical and radiological outcome was assessed for 50 of 127 eligible patients after a mean of 8.1 years. Based on postoperative radiographs the patients were dichotomized in those with a pseudarthrosis (group A) and those with solid arthrodesis (group B).

Results: Pseudarthrosis with movement of more than 2 of the operated segment was noted in 17 cases (group A). In 33 cases no movement of the vertebral segment could be detected (group B). The analysis of the clinical data assessed through the neck disability index (NDI), the visual analogue scale (VAS) of neck and arm pain and Odom's criteria did not show any significant differences between the groups.

Patients from group B showed a trend to higher adjacent segment degeneration (ASD) than group A ( $p=0.06)$.

This correlated with the age of the patients.
\end{abstract}

Conclusions: PMMA assisted discectomy shows a high rate of pseudarthrosis. But the clinical long-term success does not seem to be negatively affected by this.

\section{Background}

Ventral microdiscectomy and fusion are currently the golden standard in surgical treatment of degenerative disc disease (DDD)[1-3]. There is nevertheless an ongoing discussion as to which fusion substrate provides the best clinical and radiological outcome. Autologous iliac bone crest, allograft bone, titanium, polyetheretherketone (PEEK) or carbon cages are widely used graft materials. Polymethylmethacrylate (PMMA) is another substitute for removed discs [4], but there have been reports of higher rates of graft migration and pseudarthrosis for PMMA

\footnotetext{
* Correspondence: mario.cabraja@charite.de

Department of Neurosurgery, Charité-Universitätsmedizin Berlin, Berlin, Germany
}

C 2011 Cabraja et al; licensee BioMed Central Ltd. This is an Open Access article distributed under the terms of the Creative Commons Attribution License (http://creativecommons.org/licenses/by/2.0), which permits unrestricted use, distribution, and reproduction in any medium, provided the original work is properly cited. compared to carbon- or titanium cages [5-7]. Another major concern with using PMMA in ventral discectomy is unsatisfying results in restoring disc height and sagittal alignment $[1,7,8]$. Nevertheless, PMMA is an economic alternative to titanium and PEEK implants $[9,10]$.

The concept of spinal fusion in the treatment of DDD is currently being questioned as recent developments in spinal surgery move towards preservation rather than restriction of motion. Therefore, PMMA's poor results in regard to pseudarthrosis might be of much less relevance for the clinical outcome as previously assumed.

The aim of the present study was to evaluate the clinical outcome of patients suffering from DDD with pseudarthrosis (group A) and solid arthrodesis (group B) following PMMA-assisted discectomy and compare the 
degeneration of the adjacent segments and sagittal alignment of both groups in a long term follow-up.

\section{Methods}

From 1986 to 2004 a total of 416 patients underwent ventral discectomy and PMMA interposition. The surgical procedures were performed by two senior neurosurgeons. For better clinical comparison patients suffering from myelopathy or traumatic spinal cord injury were excluded for the purpose of this study. To evaluate adjacent segments, patients operated on segments C3-4 and C7-T1 were excluded from the study (see Figure 1) as well.

The research was conducted conforming to the Helsinki Declaration as well as local legislation. By ensuring the patient's anonymity approval from our institution's ethics committee is not required for a retrospective study.

The included patients described radiculopathy and neck pain as their main symptoms. The patients did not profit from conservative treatment. Radiographic examinations included plain radiography, MRI, CT and myelography.

The ventral discectomy was performed in supine position by a transverse skin incision from the right side after

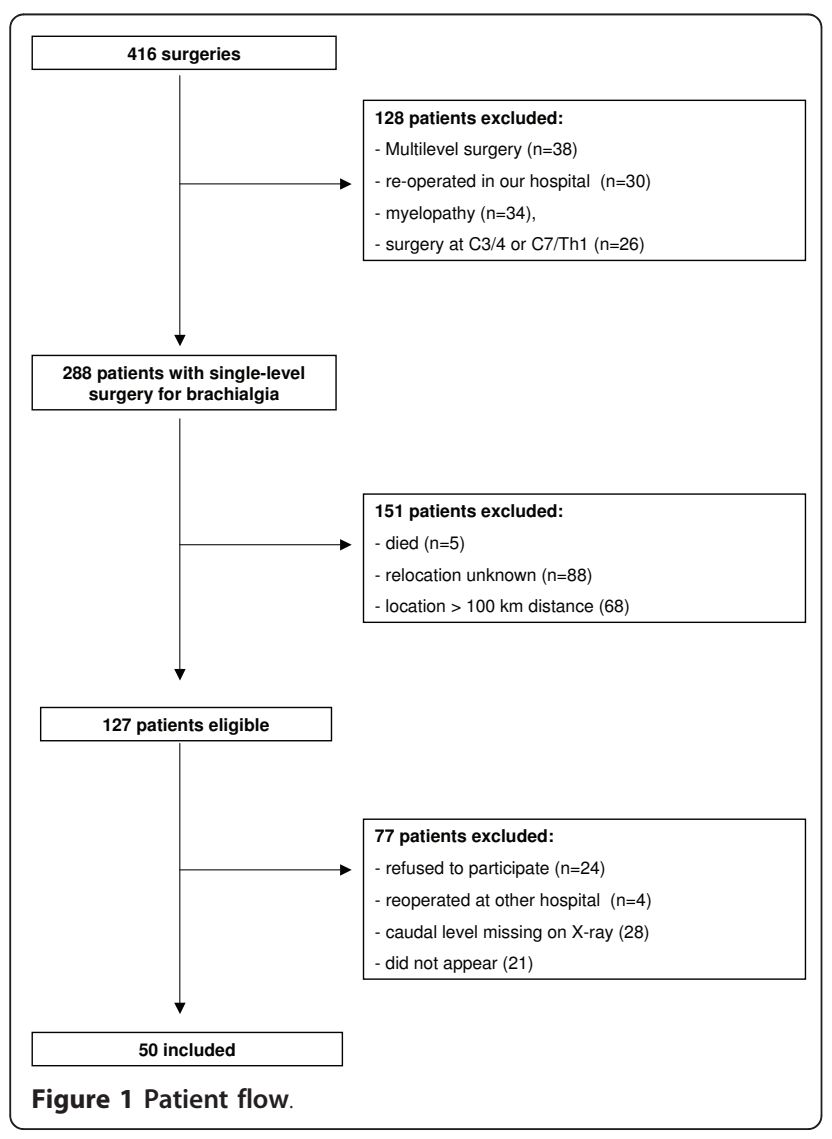

induction of general anaesthesia. After disc removal and decompression the interspace was drilled with a $5 \mathrm{~mm}$ drill under anterior distraction to create a groove in the middle part of each endplate. This was done to embed the PMMA in the disc space to prevent graft dislocation. Before application of PMMA a gelatine foam was placed in the disc space to protect the dura and nerve roots. Then the PMMA (Palacos ${ }^{\circledR} R$, Biomet Merck, and Refoba$\operatorname{cin}^{\circledR}$ Bone Cement R, Biomet Europe Group, Dordrecht, The Netherlands; Sulzer Comp., Baar, Switzerland) was inserted into the disc space with a syringe. The situs was rinsed with saline solution until the PMMA hardened. Afterwards the interbody distraction was released.

Post surgery the patients were all treated with the same protocol which consisted of physical rest for 6 weeks and then physical therapy.

Clinical examination and radiographs including plain and flexion-extension films were performed on an outpatient basis in our department. Neck and arm pain were measured by Visual Analogue Scale (VAS); functionality was assessed by the Neck Disability Index (NDI). General clinical outcome was rated using Odom's criteria.

Radiological analysis involved the measurement of three angles. The cervical lordosis was measured between $\mathrm{C} 2$ and $\mathrm{C} 7$ according to Cobb in neutral position as well as in extension and flexion. The segmental angles of the operated and adjacent vertebral levels were also measured in neutral position and in extension and flexion.

Adjacent segment degeneration (ASD) was defined as changes on plain radiographs at segments adjacent to the previously operated [11] and disc height reduction compared to a neighboring unimpaired disc $[12,13]$.

We dichotomized the patients in two groups so as to best compare clinical and radiological outcome: Movement of more than 2 shown on flexion/extension radiographs and/or the presence of radiolucency around the graft was regarded as pseudarthrosis (group A) $[2,3]$. The absence of motion between the spinous process and the bodies shown on flexion-extension lateral radiographs of the operated segment was rated as solid arthrodesis (group B) according to accepted criteria $[3,14]$.

The statistical evaluation was performed using PASW Statistics 18, Version 18.0.0 (SPSS Inc.). Statistical analysis of ASD and gender was performed by Pearson's chi-square test. The clinical and radiological data were analysed by the Mann-Whitney-U-test and the Student's t-test. A $\mathrm{p}$-value $<0.05$ was deemed as statistically significant.

\section{Results}

50 of 127 eligible patients ( 22 men and 28 women) were evaluated. The patients' age at time of operation ranged from 44 to 79 years with a mean of 58.1 years. 
Ventral discectomies were performed in 5 cases on $\mathrm{C} 4 / 5$, in 29 cases on $\mathrm{C} 5 / 6$ and in 16 cases on C6/7. The follow-up period ranged from 61 to 250 months (mean: 98 months). Implantation of the PMMA grafts was performed without complications. Intra- or postoperative graft dislocation did not occur.

Pseudarthrosis was observed in 17 cases (34\%, group A). In 33 cases no movement could be found (66\%, group B).

Both groups showed no differences in sagittal cervical and segmental lordosis $(\mathrm{p}>0.08)$. In accordance with our criteria the patients of group B did not demonstrate any movement of the operated segment, while in group A a movement of $5.8 \pm 0.7$ was measured. ROM of the cervical spine was significantly higher in group $\mathrm{A}(\mathrm{p}=$ 0.008) (Table 1). ROM of the adjacent segments did not differ significantly between the two groups $(p=0.1$ ).

Patients of group B (59.8 \pm 9.5 years) were significantly older than the patients of group A $(54.4 \pm 8.2$ years) $(p=0.027)$. The interval between surgery and assessment for the sake of this study was significantly longer $(\mathrm{p}=0.034)$ in group B $(109.6 \pm 43.5$ months $)$ than in group A (80.8 \pm 34.9 months) (Table 2$)$.

ASD could be found in 35 cases (70\%) (Figure 2) with 9 patients belonging to group A (25.7\%) and 26 patients to group B (74.3\%) (Figure 3$)$. In 15 cases (30\%) no signs of ASD was found using radiological imaging, 8 of these 15 cases belonging to group A (46.7\%), 7 to group B (53.3\%). Statistical analysis showed a trend $(\mathrm{p}=0.06)$ when comparing signs of ASD in both groups (Table 2). The patients' age had a significantly higher impact on the development of ASD ( $p=0.011)$ than the motion of the operated segment $(\mathrm{p}=0.06)$.

$60.6 \%(n=20)$ of group B showed an excellent or good outcome. In group A $76.5 \%(n=13)$ of the patients rated an excellent or good clinical outcome according to Odom's criteria, although the analysis of the clinical data did not show any significant differences in the two groups when assessed by NDI $(p=0.418)$, VAS ( $p>0.346)$ and Odom's criteria $(p=0.18)$ (Tables 3 and 4). Comparing the clinical outcome (NDI, VAS and Odom's) of patients with signs of ASD and those

Table 1 Cervical Lordosis and Range of Motion

\begin{tabular}{llll}
\hline & Group A & Group B & p-value \\
\hline C2-7, plain & $10.3 \pm 2.9$ & $9.2 \pm 2.2$ & 0.774 \\
Operated segment, plain & $2.7 \pm 0.6$ & $1.2 \pm 0.5$ & 0.082 \\
C2-7 ROM & $43.0 \pm 3.1$ & $33.7 \pm 1.8$ & 0.008 \\
Operated segment ROM & $5.8 \pm 0.7$ & $0 \pm 0$ & $<0.0001$ \\
cranial segment ROM & $10.3 \pm 1.0$ & $8.0 \pm 0.9$ & 0.110 \\
caudal segment ROM & $9.5 \pm 1.2$ & $7.1 \pm 0.7$ & 0.084 \\
\hline
\end{tabular}

Mean lordosis angle in plain scans $\left[{ }^{\circ}\right]$ and mean sagittal range of motion $(\mathrm{ROM})$ in flexion-extension scans $\left[^{\circ}\right]$ with SEM.
Table 2 Adjacent Segment Degeneration

\begin{tabular}{lllll}
\hline & ASD & no ASD & $\begin{array}{l}\text { Age } \\
\text { (years) }\end{array}$ & $\begin{array}{l}\text { Time interval } \\
\text { (months) }\end{array}$ \\
\hline Group A $(\mathbf{n}=\mathbf{1 7})$ & $9(52.9 \%)$ & $8(47.1 \%)$ & $54.4 \pm 8.2$ & $80.8 \pm 34.9$ \\
Group B $(\mathbf{n}=\mathbf{3 3})$ & $26(78.8 \%)$ & $7(21.2 \%)$ & $59.8 \pm 9.5$ & $109.6 \pm 43.5$ \\
p-value & 0.06 & 0.06 & 0.027 & 0.034
\end{tabular}

Patients with and without adjacent segment degeneration (ASD)

dichotomized in patients with pseudarthrosis (group A) and solid arthrodesis (group B) of the operated segment.

without signs of ASD did not reveal any significant clinical differences either $(\mathrm{p}>0.527)$.

\section{Discussion}

We present a retrospective long-term follow-up study of patients with a high rate (34\%) of pseudarthrosis after PMMA-assisted ventral discectomy. No statistically relevant differences in clinical outcome could be found in patients with pseudarthrosis (group A) versus patients with solid arthrodesis (group B) of the operated segment. Signs of ASD could be detected more often in the group of patients with solid arthrodesis (group B), but the appearance of ASD correlated rather with the patients' age than with the movement of the operated segment.

\section{Pseudarthrosis and PMMA}

The high rate of failed fusion and pseudarthrosis (ranging from 54-98\%) is regarded as the major disadvantage of PMMA $[7,8,15,16]$. The bone cement in the disc space does not allow a complete bony fusion. Taking this into account our results still go conform with prior studies that the clinical outcome of patients undergoing ventral discectomy and PMMA-assisted fusion does not seem to differ substantially from patients treated with other substrates $[1,5,7,8,17]$. An adequate fusion can also be achieved with filled PMMA-cages [18].

The existing literature (see table 5) dealing with PMMA-assisted cervical discectomy lacks data on

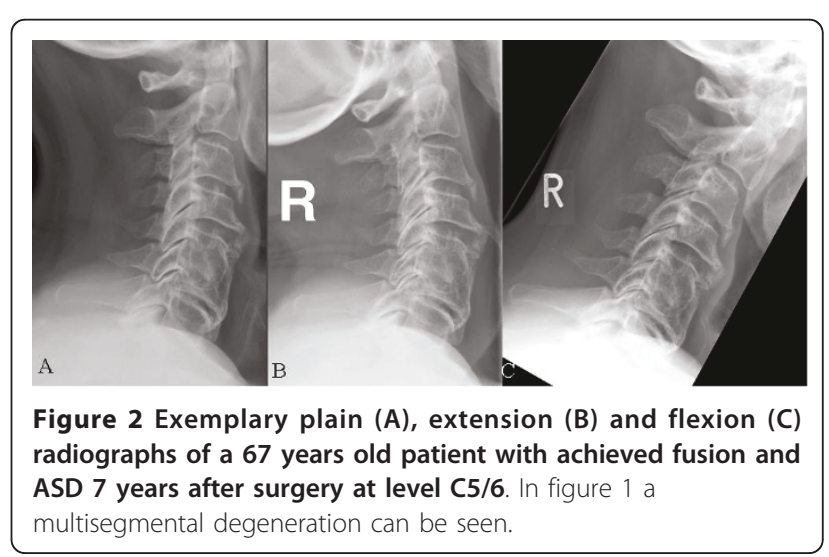



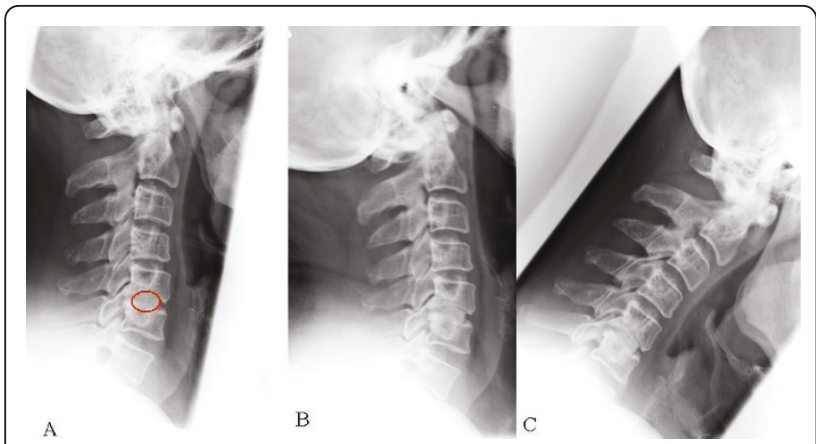

Figure 3 Exemplary plain (A), extension (B) and flexion (C) radiographs of a 57 year old patient with pseudarthrosis of the operated level and without signs of ASD 7 years after surgery. The operated pseudarthrotic level C $5 / 6$ is indexed, and the spheric form of the graft material has the aim to prevent migration (A)

segmental and cervical motion and the situation of the adjacent segments. ROM of the operated segment in group A of our study (5.8) was almost comparable to physiologic ROM [19-22]. Pseudarthrosis of the operated segments does not seem to influence the adjacent segments negatively.

\section{Cervical alignment}

Good or excellent clinical outcome can be achieved for the majority of cases by anterior cervical discectomy alone without fusion [23]. But this procedure is associated with longer postoperative neck pain [24]. Furthermore a kyphotic cervical alignment might develop or, in case of preoperative kyphotic curvature, lordotic alignment cannot be achieved [25]. These points will be critically analyzed in a prospective randomized multicenter trial (NECK-trial)[26]. The use of PMMA for fusion has been criticized to have a similar disadvantage as the intervertebral space can only be filled by PMMA and does not allow an intervertebral fusion. In our study sample a lordotic angle of the operated segment could be found in the vast majority of cases. It is to be noted that the disc space was distracted anterior before PMMA filling and released only after end of the PMMA hardening process. Thus lordotic alignment can be achieved with PMMA by anterior distraction and placement of the PMMA in the anterior or in the middle part.

\section{Table 3 Clinical Outcome}

\begin{tabular}{llll}
\hline & Group A & Group B & p-value \\
\hline NDI & $11.6 \pm 1.6$ & $13.7 \pm 1.6$ & 0.418 \\
VAS neck & $3.5 \pm 0.6$ & $2.8 \pm 0.4$ & 0.346 \\
VAS right arm & $1.3 \pm 0.5$ & $1.8 \pm 0.4$ & 0.40 \\
VAS left arm & $2.1 \pm 0.6$ & $1.8 \pm 0.4$ & 0.678 \\
\hline
\end{tabular}

Clinical outcome of both groups assessed by the neck disability index (NDI) and visual analogue scale (VAS).
Table 4 Odom's Criteria

\begin{tabular}{lll}
\hline & Group A & Group B \\
\hline Excellent & $8(47.1 \%)$ & $12(36.4 \%)$ \\
Good & $5(29.4 \%)$ & $8(24.2 \%)$ \\
Fair & $4(23.5 \%)$ & $8(24.2 \%)$ \\
Poor & 0 & $5(15.2 \%)$ \\
\hline
\end{tabular}

Overall clinical outcome according to Odom's criteria of both groups.

The presented study however lacks preoperative data. It is not known if the lordotic posture of the cervical spine increased, decreased or was maintained from its status before the operation. However, the postoperative cervical lordosis of approximately 10 in both our study groups does not differ from patients that undergo fusion surgery or cervical arthroplasty $[20,27]$.

Graft dislocation and graft breakage [5-7,25,28] have not been found during the course of our long-term study. The described technique of embedding the PMMA offers a possible explanation for these results.

\section{Clinical outcome}

Whether osseous fusion is necessary for a favourable outcome after cervical discectomy is subject of a controversial discussion [25]. Out study shows that PMMA does not offer inferior long term clinical results even though segmental fusion is inferior compared to other allograft substitutes [1].

Our comparably low rate of excellent and good outcome $(60.6 \%)$ can be explained with a significantly longer follow-up period compared to most of the listed studies (Table 5). We also differentiated between arm and neck pain. Our patients experienced substantial relief of their brachialgia, but still complained of neck pain (see table 3), which could be related to the natural course of the degenerative disease.

The findings of ASD did not affect clinical outcome.

\section{Range of motion}

Despite a longer follow-up period the cervical C2-7 ROM of our study groups (Group A 43.0, Group B 33.7) was almost comparable to patients undergoing fusion surgery or arthroplasty in prospective studies 2 years after surgery (39.6 after fusion and 53.2 after arthroplasty) $[29,30]$.

Due to different kinematics of the upper cervical spine (C1-3) and our specifically determined interest in ASD of cranial as well as caudal levels patients operated on C3-4 and C7/T1 were excluded from our study.

$25 \%$ to $92 \%$ of patients undergoing cervical surgery develop ASD within 4.5 to 8 years [12,31-33]. The high prevalence of ASD 8 years after surgery in our group B goes conform with these findings of previous studies, but might be a consequence of a higher preoperative 
Table 5 Overview of PMMA-studies in the last 20 years

\begin{tabular}{|c|c|c|c|c|c|c|}
\hline Author, Year & $\begin{array}{l}\text { Study design, } \\
\text { follow-up }\end{array}$ & Material & No. of patients & Clinical outcome & Fusion according to author & Re-OP \\
\hline Böker et al., 1989 [15] & $\begin{array}{l}\text { Retrospective } \\
15-20 \text { years }\end{array}$ & PMMA & 57 & not assessed & $89 \%$ & 0 \\
\hline Samii et al., 1989 [16] & $\begin{array}{l}\text { Retrospective } \\
4.8 \text { years }\end{array}$ & PMMA & 438 & $81 \%$ pain relief & not assessed & $35(8 \%)$ \\
\hline van den Bent et al., 1996 [7] & $\begin{array}{l}\text { Prospective } \\
2 \text { years }\end{array}$ & $\begin{array}{l}\text { PMMA } \\
\text { MDO }\end{array}$ & $\begin{array}{l}42 \\
39\end{array}$ & $\begin{array}{l}70 \% \text { good } \\
77 \% \text { good }\end{array}$ & $\begin{array}{l}28 \% \\
63 \%\end{array}$ & $\begin{array}{l}0 \\
0\end{array}$ \\
\hline Hamburger et al., 2001 [8] & $\begin{array}{l}\text { Retrospective } \\
12.2 \text { years }\end{array}$ & PMMA & 249 & $77.5 \%$ exc. or good & $53.8 \%$ & $24(9.6 \%)$ \\
\hline Jöllenbeck et al., 2001 [10] & $\begin{array}{l}\text { Prospective } \\
7 \text { days }\end{array}$ & $\begin{array}{l}\text { PMMA } \\
\text { TTC }\end{array}$ & $\begin{array}{l}100 \\
100\end{array}$ & $\begin{array}{l}81 \% \text { compl. recovery } \\
78 \% \text { " }\end{array}$ & not assessed & $\begin{array}{l}1(1 \%) \\
1(1 \%)\end{array}$ \\
\hline Bärlocher et al., 2002 [1] & $\begin{array}{l}\text { Prospective } \\
1 \text { year }\end{array}$ & $\begin{array}{l}\text { MDO } \\
\text { ABG } \\
\text { PMMA } \\
\text { TTC }\end{array}$ & $\begin{array}{l}33 \\
30 \\
26 \\
36\end{array}$ & $\begin{array}{l}75.5 \% \text { exc. or good } \\
80 \% " \\
87.5 \% " \\
94.4 \% "\end{array}$ & $\begin{array}{l}93.3 \% \\
65.3 \% \\
0 \% \\
97.2 \%\end{array}$ & $\begin{array}{l}2(6.1 \%) \\
1(3.3 \%) \\
0 \\
0\end{array}$ \\
\hline Chen et al., 2005 [18] & $\begin{array}{l}\text { Prospective } \\
2 \text { years }\end{array}$ & PMMA-cage & 63 & $100 \%$ exc. or good & $100 \%$ & 0 \\
\hline Korinth et al., 2006 [17] & $\begin{array}{l}\text { Retrospective } \\
6 \text { years }\end{array}$ & PMMA & 124 & $93.6 \%$ exc. or good & not assessed & $3(2.4 \%)$ \\
\hline Schröder et al., 2007 [5] & $\begin{array}{l}\text { Prospective } \\
2 \text { years }\end{array}$ & $\begin{array}{l}\text { PMMA } \\
\pi C\end{array}$ & $\begin{array}{l}53 \\
54\end{array}$ & $\begin{array}{l}85 \% \text { exc. or good } \\
77.7 \% " \text { " }\end{array}$ & $\begin{array}{l}66 \% \\
87 \%\end{array}$ & $\begin{array}{l}0 \\
0\end{array}$ \\
\hline
\end{tabular}

Overview of studies in the last 20 years evaluating the outcome of patients with DDD treated with ventral discectomy and PMMA-assisted fusion.

$\mathrm{MDO}=$ Microdiscetomy only; $\mathrm{ABG}=$ autologous bone graft; $\mathrm{TC}=$ titanium cage

prevalence as well. It is also to be noted that the patients of our group B were significantly older (5.4 years) and were examined after a significantly longer period (28.8 months) following surgery. In contrast to previous studies the detection of ASD in our study did not correlate with the time interval between surgery and last follow-up [12], but only with the age of the patients.

The prevalence of adjacent segment disease ranges from 9 to $14 \%$ following fusion [8,32,34-37]. Our overall collective $(n=416)$ comprised of 34 patients $(8.2 \%)$ that had been excluded because of the need for surgery of an adjacent level. It is not known if the previously operated segment of these patients was pseudarthrotic or solid before the second surgery.

Preoperative plain or functional imaging was available only in a small number of our patients. Therefore our study lacks preoperative imaging of the cervical spine for better comparison with the postoperative radiological status.

Whether ASD or adjacent segment disease is a consequence of previous stabilizing surgery or the natural course of the disease [33,38] as indicated by the higher age and longer follow-up period of our group B remains controversial.

\section{Conclusions}

Ventral discectomy and fusion with PMMA represents a cheap, safe and successful procedure in the treatment of cervical DDD. Although the rate of pseudarthrosis following PMMA-assisted cervical surgery is comparably high, clinical outcome does not differ from that of patients with successful solid arthrodesis. Furthermore we could show that cervical lordosis can be achieved with PMMA by distraction of intervertebral space. This data might justify a randomized multicenter study with PMMA as a substrate alongside recently more accepted materials as PEEK, carbon and titanium.

\section{Abbreviations}

ABG: autologous bone graft; ASD: adjacent segment degeneration; DDD: degenerative disc disease; MDO: Microdiscetomy only; NDI: neck disability index; PEEK: polyetheretherketone; PMMA: polymethylmethacrylate; ROM: range of motion; SEM: standard error of the mean; TTC: titanium cage; VAS: visual analogue scale.

\section{Acknowledgements and funding}

We thank Mrs. Leah Hecker for editing the manuscript.

\section{Authors' contributions}

MC was responsible for conception, design, data analysis, writing and editing of the MS. DK was responsible for data analysis, writing and editing of the MS, WL was responsible for data analysis, writing and editing, KM was responsible for data analysis, writing and editing, SK was responsible for conception, design, data analysis, writing and editing of the MS. All authors read and approved the final manuscript.

\section{Competing interests}

The authors declare that they have no competing interests.

Received: 9 December 2010 Accepted: 28 June 2011 Published: 28 June 2011

\section{References}

1. Barlocher CB, Barth A, Krauss JK, Binggeli R, Seiler RW: Comparative evaluation of microdiscectomy only, autograft fusion, polymethylmethacrylate interposition, and threaded titanium cage fusion for treatment of single-level cervical disc disease: a 
prospective randomized study in 125 patients. Neurosurg Focus 2002, 12(1):E4.

2. Hacker RJ: A randomized prospective study of an anterior cervical interbody fusion device with a minimum of 2 years of follow-up results. J Neurosurg 2000, 93(2 Suppl):222-226.

3. Hacker RJ, Cauthen JC, Gilbert TJ, Griffith SL: A prospective randomized multicenter clinical evaluation of an anterior cervical fusion cage. Spine (Phila Pa 1976) 2000, 25(20):2646-2654, discussion 2655.

4. Grote $W$, Rottgen P: [The ventral fusion in cervical osteochondrosis and its treatment results]. Acta Neurochir (Wien) 1967, 16(3):218-240.

5. Schroder J, Grosse-Dresselhaus F, Schul C, Wassmann H: PMMA versus titanium cage after anterior cervical discectomy - a prospective randomized trial. Zentralb/ Neurochir 2007, 68(1):2-7.

6. Schroder J, Wassmann H: [Polymethylmethacrylate (PMMA) in anterior cervical spine surgery - current situation in Germany]. Zentralb/ Neurochir 2001, 62(2):33-36.

7. van den Bent MJ, Oosting J, Wouda EJ, van Acker RE, Ansink BJ, Braakman R: Anterior cervical discectomy with or without fusion with acrylate. A randomized trial. Spine (Phila Pa 1976) 1996, 21(7):834-839, discussion 840.

8. Hamburger C, Festenberg FV, Uhl E: Ventral discectomy with pmma interbody fusion for cervical disc disease: long-term results in 249 patients. Spine (Phila Pa 1976) 2001, 26(3):249-255.

9. Vieweg U: [Possibilities for cost reduction of implants in spinal surgery]. Zentralbl Neurochir 2003, 64(4):159-165.

10. Jollenbeck B, Fernandez N, Firsching R: Titanium or polymethylmethacrylate in cervical disc surgery? A prospective study. Zentralbl Neurochir 2001, 62(4):200-202.

11. Hilibrand AS, Robbins M: Adjacent segment degeneration and adjacent segment disease: the consequences of spinal fusion? Spine J 2004, 4(6 Suppl):190S-194S.

12. Goffin J, Geusens E, Vantomme N, Quintens E, Waerzeggers Y, Depreitere B, Van Calenbergh F, van Loon J: Long-term follow-up after interbody fusion of the cervical spine. J Spinal Disord Tech 2004, 17(2):79-85.

13. Hilibrand AS, Carlson GD, Palumbo MA, Jones PK, Bohlman HH: Radiculopathy and myelopathy at segments adjacent to the site of a previous anterior cervical arthrodesis. J Bone Joint Surg Am 1999, 81(4):519-528.

14. Dorai $\mathrm{Z}$, Morgan $\mathrm{H}$, Coimbra C: Titanium cage reconstruction after cervical corpectomy. J Neurosurg 2003, 99(1 Suppl):3-7.

15. Boker DK, Schultheiss R, Probst EM: Radiologic long-term results after cervical vertebral interbody fusion with polymethyl methacrylat (PMMA). Neurosurg Rev 1989, 12(3):217-221.

16. Samii M, Volkening D, Sepehrnia A, Penkert G, Baumann H: Surgical treatment of myeloradiculopathy in cervical spondylosis. A report on 438 operations. Neurosurg Rev 1989, 12(4):285-290.

17. Korinth MC, Kruger A, Oertel MF, Gilsbach JM: Posterior foraminotomy or anterior discectomy with polymethyl methacrylate interbody stabilization for cervical soft disc disease: results in 292 patients with monoradiculopathy. Spine (Phila Pa 1976) 2006, 31(11):1207-1214, discussion 1215-1206.

18. Chen JF, Wu CT, Lee SC, Lee ST: Use of a polymethylmethacrylate cervical cage in the treatment of single-level cervical disc disease. J Neurosurg Spine 2005, 3(1):24-28.

19. Heidecke V, Burkert W, Brucke M, Rainov NG: Intervertebral disc replacement for cervical degenerative disease-clinical results and functional outcome at two years in patients implanted with the Bryan cervical disc prosthesis. Acta Neurochir (Wien) 2008, 150(5):453-459, discussion 459.

20. Heller JG, Sasso RC, Papadopoulos SM, Anderson PA, Fessler RG, Hacker RJ, Coric D, Cauthen JC, Riew DK: Comparison of BRYAN cervical disc arthroplasty with anterior cervical decompression and fusion: clinical and radiographic results of a randomized, controlled, clinical trial. Spine (Phila Pa 1976) 2009, 34(2):101-107.

21. Murrey D, Janssen M, Delamarter R, Goldstein J, Zigler J, Tay B, Darden B: Results of the prospective, randomized, controlled multicenter Food and Drug Administration investigational device exemption study of the ProDisc-C total disc replacement versus anterior discectomy and fusion for the treatment of 1-level symptomatic cervical disc disease. Spine $J$ 2009, 9(4):275-286
22. Sasso RC, Smucker JD, Hacker RJ, Heller JG: Artificial disc versus fusion: a prospective, randomized study with 2-year follow-up on 99 patients. Spine (Phila Pa 1976) 2007, 32(26):2933-2940, discussion 2941-2932.

23. Hadley MN, Sonntag VK: Cervical disc herniations. The anterior approach to symptomatic interspace pathology. Neurosurg Clin N Am 1993, 4(1):45-52.

24. Watters WC, Levinthal R: Anterior cervical discectomy with and without fusion. Results, complications, and long-term follow-up. Spine (Phila Pa 1976) 1994, 19(20):2343-2347

25. Sonntag VK, Klara P: Controversy in spine care. Is fusion necessary after anterior cervical discectomy? Spine (Phila Pa 1976) 1996, 21(9):1111-1113.

26. Arts MP, Brand R, van den Akker E, Koes BW, Peul WC: The NEtherlands Cervical Kinematics (NECK) Trial. Cost-effectiveness of anterior cervical discectomy with or without interbody fusion and arthroplasty in the treatment of cervical disc herniation; a double-blind randomised multicenter study. BMC Musculoskelet Disord 11:122.

27. Yoon DH, Yi S, Shin HC, Kim KN, Kim SH: Clinical and radiological results following cervical arthroplasty. Acta Neurochir (Wien) 2006, 148(9):943-950.

28. Schroder J: Use of polymethylmethacrylate (PMMA). Spine (Phila Pa 1976) 2001, 26(23):2638.

29. Kim SW, Limson MA, Kim SB, Arbatin JJ, Chang KY, Park MS, Shin JH, Ju YS: Comparison of radiographic changes after ACDF versus Bryan disc arthroplasty in single and bi-level cases. Eur Spine J 2009, 18(2):218-231.

30. Kim SW, Shin JH, Arbatin JJ, Park MS, Chung YK, MCAfee PC: Effects of a cervical disc prosthesis on maintaining sagittal alignment of the functional spinal unit and overall sagittal balance of the cervical spine. Eur Spine J 2008, 17(1):20-29.

31. Baba H, Furusawa N, Imura S, Kawahara N, Tsuchiya H, Tomita K: Late radiographic findings after anterior cervical fusion for spondylotic myeloradiculopathy. Spine (Phila Pa 1976) 1993, 18(15):2167-2173.

32. Gore DR, Sepic SB: Anterior cervical fusion for degenerated or protruded discs. A review of one hundred forty-six patients. Spine (Phila Pa 1976) 1984, 9(7):667-671

33. Herkowitz HN, Kurz LT, Overholt DP: Surgical management of cervical soft disc herniation. A comparison between the anterior and posterior approach. Spine (Phila Pa 1976) 1990, 15(10):1026-1030.

34. Bohlman HH, Emery SE, Goodfellow DB, Jones PK: Robinson anterior cervical discectomy and arthrodesis for cervical radiculopathy. Longterm follow-up of one hundred and twenty-two patients. J Bone Joint Surg Am 1993, 75(9):1298-1307.

35. Ishihara H, Kanamori M, Kawaguchi Y, Nakamura H, Kimura T: Adjacent segment disease after anterior cervical interbody fusion. Spine J 2004 4(6):624-628.

36. Robertson JT, Papadopoulos SM, Traynelis VC: Assessment of adjacentsegment disease in patients treated with cervical fusion or arthroplasty: a prospective 2-year study. J Neurosurg Spine 2005, 3(6):417-423.

37. Yue WM, Brodner W, Highland TR: Long-term results after anterior cervical discectomy and fusion with allograft and plating: a 5- to 11-year radiologic and clinical follow-up study. Spine (Phila Pa 1976) 2005, 30(19):2138-2144.

38. Gore DR: Roentgenographic findings in the cervical spine in asymptomatic persons: a ten-year follow-up. Spine (Phila Pa 1976) 2001, 26(22):2463-2466.

\section{Pre-publication history}

The pre-publication history for this paper can be accessed here: http://www.biomedcentral.com/1471-2474/12/140/prepub

doi:10.1186/1471-2474-12-140

Cite this article as: Cabraja et al:: Polymethylmethacrylate-assisted ventral discectomy: Rate of pseudarthrosis and clinical outcome with a minimum follow-up of 5 years. BMC Musculoskeletal Disorders 2011 12:140. 